Asian Australas. J. Food Saf. Secur. 2019, 3 (2), 96-102

Asian-Australasian Journal of

Food Safety and Security

ISSN 2523-1073 (Print) 2523-2983 (Online)

www.ebupress.com/journal/aajfss

\title{
Article \\ Discriminate and indiscriminate use of amoxicillin antibiotic and detection of its residue in poultry edible tissue by thin layer chromatography (TLC) method
}

\author{
Md. Shakil Islam, Md. Zahorul Islam and Md. Shafiqul Islam* \\ Department of Pharmacology, Faculty of Veterinary Science, Bangladesh Agricultural University, \\ Mymensingh-2202, Bangladesh
}

${ }^{*}$ Corresponding author: Professor Dr. Md. Shafiqul Islam, Department of Pharmacology, Bangladesh Agricultural University, Mymensingh-2202, Bangladesh. E-mail:shafiqpharma@yahoo.co.uk

Received: 03 November 2019/Accepted: 27 November 2019/ Published: 30 November 2019

\begin{abstract}
Antibiotic residue is a burning question in the present world. Antibiotic remain in edible tissues of poultry as a residue due to indiscriminate use in the veterinary field. Human health is at risk of antibiotics due to poultry edible tissues. In this study, we used broiler chicks as a laboratory animal to investigate the judicial use of amoxicillin antibiotic for human health concern. Chicks were reared accordingly and on day 14 the chicks were randomly divided into three groups $(n=6)$ namely control (group A), discriminate (group B) and indiscriminate (group C). At the age of day 16, amoxicillin treatment was started and continued for seven days for discriminate group (Group B) and 15 days for indiscriminate group. In case of discriminate group, seven days withdrawal period was properly maintained, whereas, no withdrawal period was maintained in case of indiscriminate group. In control group, no positive samples were detected by thin layer chromatography (TLC) analysis, whereas, the amoxicillin intensity in liver, kidney, thigh muscle and breast muscle were positive by TLC as $57.82 \%, 52.30 \%, 45.18 \%$ and $49.96 \%$ respectively for indiscriminate group. Similarly $46.81 \%$ liver, 44.65\% kidney, $29.27 \%$ thigh muscle and $32.73 \%$ breast muscle were the amoxicillin intensity in discriminate group. The level of amoxicillin were found significantly different between control \& discriminate, control \& indiscriminate and discriminate \& indiscriminate groups by TLC analysis. Therefore, amoxicillin residue present in both discriminate and indiscriminate group but the intensity percentage (\%) was highest in case of indiscriminate group indicates high residual concentration.
\end{abstract}

Keywords: amoxicillin; antibiotic residue; broiler

\section{Introduction}

Poultry production is the most rapidly growing industries around the globe, and poultry is one of the major sources of meat (Muaz et al., 2018). Antibiotics are used largely for three purposes in poultry industries, therapeutic use to treat sick poultry, prophylactic use to prevent infection in poultry and as growth promoters to improve feed utilization and production for their growth promoting properties they are routinely used at subtherapeutic levels as poultry feed additives (Guetiya Wadoum et al., 2016). But, indiscriminate and irrational use of antibiotics resulting in antibiotic residues in foodstuff which can pose hazards to human health and among them are sensitivity to antibiotics, allergic reactions and imbalance of intestinal microbiota are very common (Javadi et al., 2011). Antibiotic residues in foods of animal origin are one of the sources of concern among the public and medical health professionals (Singh et al., 2014). Amoxicillin is a broad-spectrum, pharmacologically active beta-lactam antibiotic (Koutoulis et al., 2015) used largely for treatment of bacterial infection in poultry industries (Alswayeh et al., 2015; Khan et al., 2018). Despite the important therapeutic use of amoxicillin in veterinary practices, relatively little has been known on the pharmacokinetic behavior and residual status of this drug in birds (Dorrestein et al., 1986). Therefore, the present study was undertaken to find 
out the antibiotic residues in broiler meat and aware the people about these residues to adopt preventive measures for their own health and welfare of the animals.

\section{Materials and Methods}

\subsection{Experimental design}

18 DOCs were collected as laboratory animal from commercial hatchery. Chicks were reared for 15 days without using any antibiotic; only feed and water. At the age of day 15 chicks were grouped in 3 experimental groups (A, B and C); each group having 10 chicks. Group A was kept as untreated control and received no antibiotic medicated water, group $\mathrm{B}$ is discriminate group and group $\mathrm{C}$ is indiscriminate group. Antibiotic treatment was started from $16^{\text {th }}$ day. Group B was administered with amoxicillin at recommended therapeutic dose @ $10 \mathrm{mg} / \mathrm{kg}$ through drinking water as described in (Anadón et al., 1996). In group C the dose of amoxicillin was indiscriminate and more than the therapeutic dose $(10 \mathrm{mg} / \mathrm{kg})$. After 7 days, at the age of day 23; antibiotic supply was stopped in the group-B and withdrawal period was maintained as drug nomenclature (7 days). In group $\mathrm{C}$ withdrawal period was not maintained and antibiotic continued till $30^{\text {th }}$ day. Liver, kidney, thigh muscle and breast muscle were collected from every bird at $30^{\text {th }}$ day.

\subsection{Chemical and standard drugs}

Purity of all standard chemicals and reagents was at least 99\%. HPLC grade methanol (Merck-Germany), trichloracetic acid (TCA), diethyl ether, butanol, distilled water and acetic acid. The standard for amoxicillin was prepared by dissolving $0.1 \mathrm{gm}$ of amoxicillin powder in $4 \mathrm{~mL}$ solution of methanol. Standard solution was stored in $-4^{\circ} \mathrm{C}$ and every month fresh solution was prepared (Sarker et al., 2018).

\subsection{Sample preparation}

Four gram of each sample was cut into small pieces, grinded and blended. $10 \mathrm{~mL}$ Phosphate Buffer Saline (pH6.5) was added and mixed by vortexing (Vortex- XHC, Wincom, China). Centrifuged (Hettich D-78532, Germany)@60000 rpm for 20 min was done after mixing with 2 mL 30\% TCA. Supernatant was collected and filtered by Whatman filter paper and funnel. Filtrated fluid was collected in another falcon tube and same amount of diethyl ether was added and left for $10 \mathrm{~min}$ in room temperature. The bottom layer was collected and supernatant extraction was repeated twice using diethyl ether. Final volume of the extracts were pooled carefully into screw cap vial and kept into refrigerator for future analysis. Total procedure was performed as the reference cited by (Popelka et al., 2005).

\subsection{Preparation of the mobile phase}

In order to perform Thin Layer Chromatography (TLC) along with the stationary phase, mobile was prepared as directed in the references (Hancu et al., 2013). The composition of mobile phase was Butanol: distilled water: acetic acid (60:20:20).

\subsection{Thin layer chromatography (TLC) \\ 2.5.1. TLC apparatus}

TLC plate (MN-Germany), TLC tank and UV detection box (UV light: F18W-Germany) were used. TLC was performed according to Tajick and Shohreh (2006) with some required adjustments. TLC plate was cut into appropriate size $(4 \times 5 \mathrm{~cm})$ from $20 \times 20 \mathrm{~cm}$. A straight line was drawn across the plate approximately $2 \mathrm{~cm}$ from the bottom by a pencil. Another straight line was drawn across the plate below $1 \mathrm{~cm}$ from the upper edge of the plate. Desired spots marking were marked on the bottom line where analytes were dropped. Spots were applied to the plate using thin capillary glass pipettes. A volume of $50 \mu \mathrm{l}$ was used for spotting. Plate was placed in TLC tank (contained mobile phase; Butanol: distilled water: acetic acid $=60: 20: 20)$ and covered by lid and it was left until the mobile phase reached the upper line. Spots were visualized in UV detection box at $256 \mathrm{~nm}$. Spots marking were done by pencil for calculation of retention factor $\left(\mathrm{R}_{\mathrm{f}}\right)$.

\subsubsection{Calculation of $\mathbf{R}_{\mathrm{f}}$ values}

These measurements are the distance travelled by the solvent, and the distance travelled by individual sample spots. Same $\mathrm{R}_{\mathrm{f}}$ value of standard and sample considered similar compound.

\subsection{Data analysis}

Experimental data were introduced and stored in Microsoft Excel-2010 and results were analyzed statistically using Graph Pad Prism Version 6. 
3. Results

3.1. Liver sample

Amoxicillin residue in liver sample of three different groups is presented in Table 1 and Figure 1. There was no positive sample in control group, however, in both discriminate and indiscriminate groups positive samples were found by TLC analysis. The multiple pairwise comparisons during one way ANOVA (Bonferroni) showed that there was significant difference between discriminate and indiscriminate groups $(\mathrm{P}<0.05, \mathrm{P}=0.049)$.

\subsection{Kidney sample}

Table 2 and Figure 2 represent amoxicillin residue in kidney sample of three different groups. In control group, we could not find any positive kidney samples. On the other hand positive samples were found by TLC analysis in both discriminate and indiscriminate groups. The multiple pairwise comparisons during one way ANOVA (Bonferroni) showed that there was significant difference between discriminate and indiscriminate groups $(\mathrm{P}<0.05, \mathrm{P}=0.026)$.

\subsection{Thigh muscle sample}

Amoxicillin residue in thigh muscle sample of three different groups is presented in Table 3 . The highest amoxicillin intensity (\%) was recorded in the indiscriminate group (45.18 \pm 3.054$)$. The amoxicillin intensity (\%) of control and discriminate groups was $0.00 \pm 0.00$ and $29.27 \pm 3.548$ respectively. There was significant difference among control, discriminate and indiscriminate group $(\mathrm{P}<0.001)$.

Figure 3 represents amoxicillin antibiotic residue in thigh muscle. In control group all thigh muscle samples were negative, however, in both discriminate and indiscriminate groups positive samples were found by TLC analysis. The multiple pairwise comparisons during one way ANOVA (Bonferroni) showed that there was significant difference between discriminate and indiscriminate groups $(\mathrm{P}<0.01, \mathrm{P}=0.003)$. The other two groups (Control \& discriminate and control \& indiscriminate) also showed significant difference $(\mathrm{P}<0.001)$.

\subsection{Breast muscle}

Amoxicillin residue in breast muscle sample of three different groups is presented in Table 4. The amoxicillin intensity (\%) in indiscriminate group was $49.96 \pm 4.024$ whereas, in discriminate group it was $32.73 \pm 2.826$ and in control group it was $0.00 \pm 0.00$. The highest amoxicillin intensity (\%) was obtained from indiscriminate group. During one way ANOVA there was significant difference among control, discriminate and indiscriminate group $(\mathrm{P}<0.001)$.

Figure 4 represents amoxicillin antibiotic residue in breast muscle. In control group all thigh muscle samples were negative, however, in both discriminate and indiscriminate groups positive samples were found by TLC analysis. The multiple pairwise comparisons during one way ANOVA (Bonferroni) showed that there was significant difference between discriminate and indiscriminate groups $(\mathrm{P}<0.01, \mathrm{P}=0.002)$. The other two groups (Control \& discriminate and control \& indiscriminate) also showed significant difference $(\mathrm{P}<0.001)$.

Table 1. Amoxicillin residue in liver sample of three different groups.

\begin{tabular}{|c|c|c|c|}
\hline $\begin{array}{l}\text { Name of } \\
\text { group }\end{array}$ & $\begin{array}{c}\text { Amoxicillin intensity in } \\
\text { liver by TLC (Mean } \pm \\
\text { SEM) }\end{array}$ & P Value & $\begin{array}{c}\text { Level of } \\
\text { Significance }\end{array}$ \\
\hline Group-A (Control group) & $0.00 \pm 0.00$ & & \\
\hline Group-B (Discriminate group) & $46.81 \pm 2.76$ & $<0.001$ & $* * *$ \\
\hline Group-C (Indiscriminate group) & $57.82 \pm 4.15$ & & \\
\hline
\end{tabular}

Table 2. Amoxicillin residue in kidney sample of three different groups.

\begin{tabular}{|c|c|c|c|}
\hline $\begin{array}{l}\text { Name of } \\
\text { group }\end{array}$ & $\begin{array}{c}\text { Amoxicillin intensity in } \\
\text { kidney by TLC (Mean } \pm \\
\text { SEM) }\end{array}$ & P Value & $\begin{array}{c}\text { Level of } \\
\text { Significance }\end{array}$ \\
\hline Group-A (Control group) & $0.00 \pm 0.00$ & & \\
\hline Group-B (Discriminate group) & $44.65 \pm 2.54$ & $<0.001$ & $* * *$ \\
\hline Group-C (Indiscriminate group) & $52.30 \pm 1.94$ & & \\
\hline
\end{tabular}


Table 3. Amoxicillin residue in thigh muscle sample of three different groups.

\begin{tabular}{lccc}
\hline $\begin{array}{l}\text { Name of } \\
\text { group }\end{array}$ & $\begin{array}{c}\text { Amoxicillin intensity in } \\
\text { thigh muscle by TLC (Mean } \\
\mathbf{\pm} \text { SEM) }\end{array}$ & P Value & $\begin{array}{c}\text { Level of } \\
\text { Significance }\end{array}$ \\
\hline Group-A (Control group) & $0.00 \pm 0.00$ & $* * *$ \\
Group-B (Discriminate group) & $29.27 \pm 3.548$ & $<0.001$ & \\
Group-C (Indiscriminate group) & $45.18 \pm 3.054$ & & \\
\hline
\end{tabular}

Table 4. Amoxicillin residue in breast muscle sample of three different groups.

\begin{tabular}{lccc}
\hline $\begin{array}{l}\text { Name of } \\
\text { group }\end{array}$ & $\begin{array}{c}\text { Amoxicillin intensity in } \\
\text { breast muscle by TLC (Mean } \\
\pm \text { SEM) }\end{array}$ & P Value & $\begin{array}{c}\text { Level of } \\
\text { Significance }\end{array}$ \\
\hline Group-A(Control group) & $0.00 \pm 0.00$ & $* * *$ \\
Group-B(Discriminate group) & $32.73 \pm 2.826$ & $<0.001$ & $*$ (Indiscriminate group) \\
Group-C(2. & $49.96 \pm 4.024$ & \\
\hline
\end{tabular}

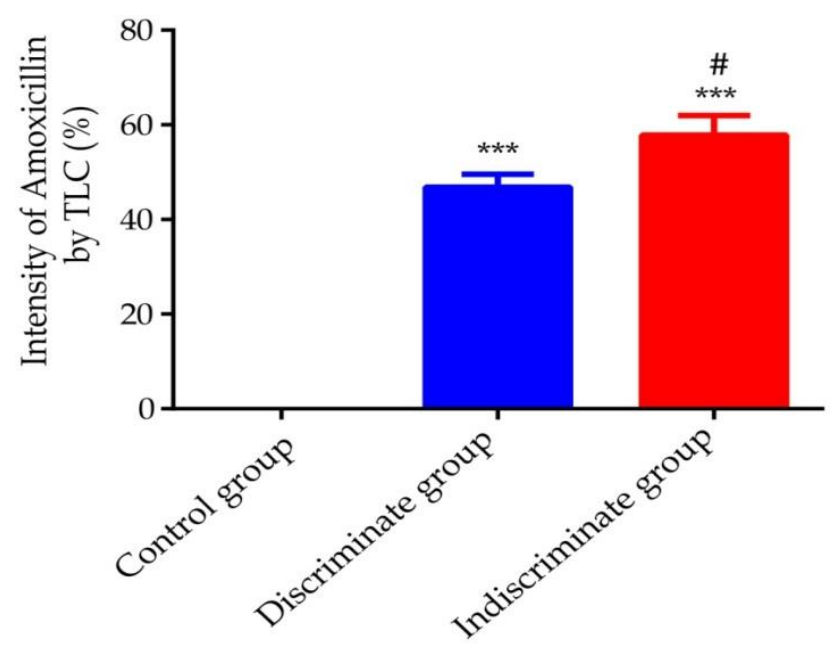

Figure 1. Amoxicillin antibiotic in liver.

***, Significantly difference between control \& discriminate groups and control \& indiscriminate groups $(\mathrm{P}<0.001)$.

\#, Significantly different between discriminate and indiscriminate groups $(\mathrm{P}<0.05)$.

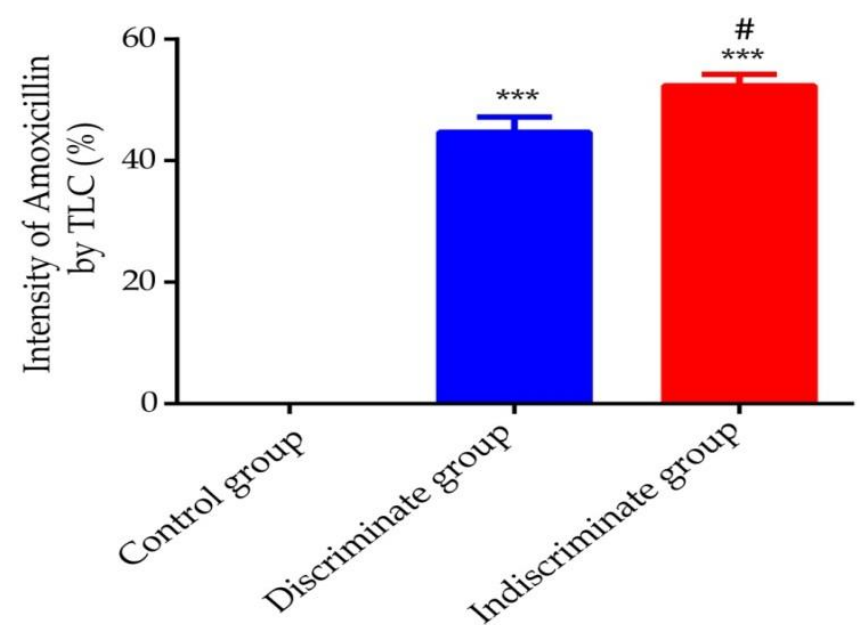

Figure 2. Amoxicillin antibiotic in kidney.

***, Significantly difference between control \& discriminate group and control \& indiscriminate groups $(\mathrm{P}<0.001)$.

\#, Significantly different between discriminate and indiscriminate groups $(\mathrm{P}<0.05)$. 


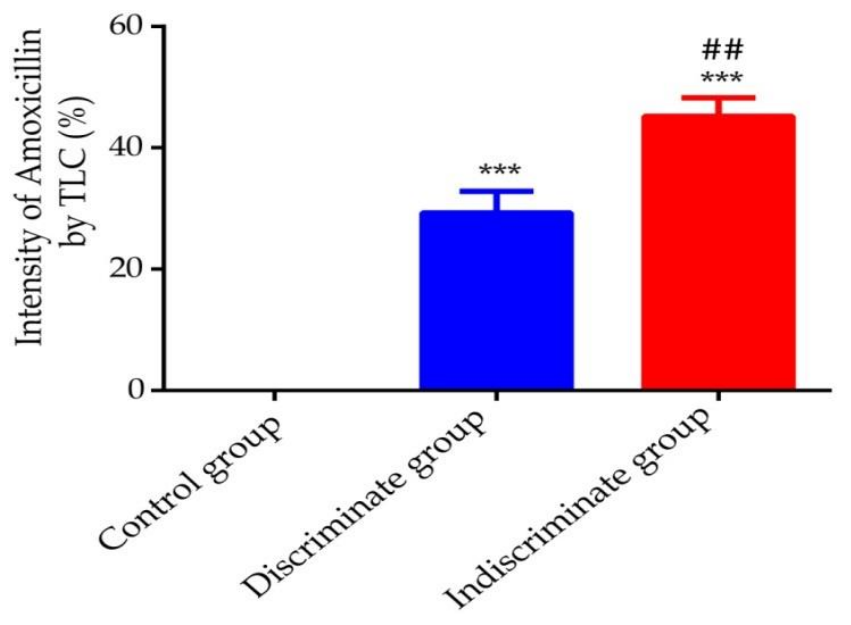

Figure 3. Amoxicillin antibiotic in thigh muscle.

***, Significantly difference between control \& discriminate group and control \& indiscriminate groups $(\mathrm{P}<0.001)$.

\#\#, Significantly different between discriminate and indiscriminate groups $(\mathrm{P}<0.01)$.

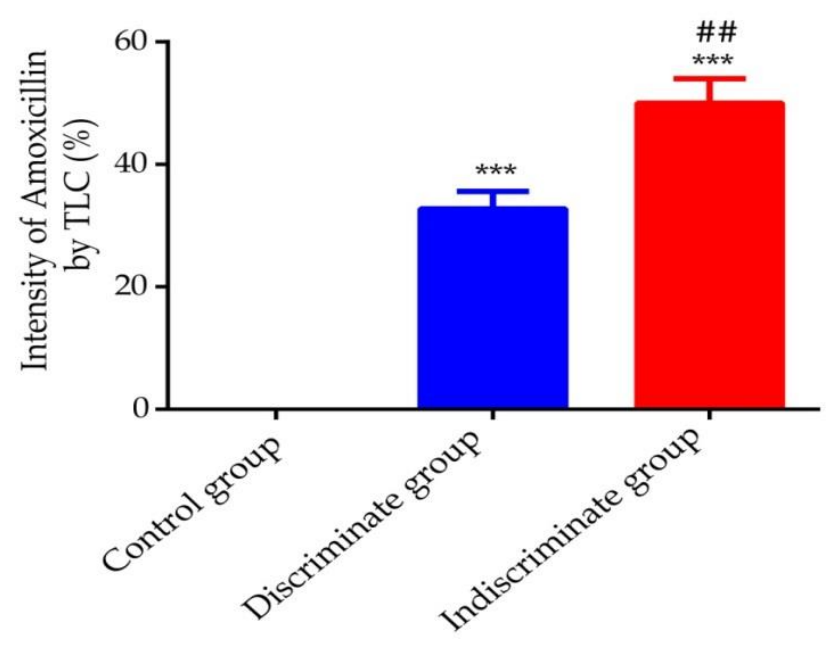

Figure 4. Amoxicillin antibiotic in breast muscle.

***, Significantly difference between control \& discriminate group and control \& indiscriminate group $(\mathrm{P}<0.001)$.

\#\#, Significantly different between discriminate and indiscriminate group $(\mathrm{P}<0.01)$.

\section{Discussion}

Chicken meat is a good source of high quality protein along with important vitamins and mineral and contains low fat (Givens, 2005). Also chicken production is quicker and cheaper than other meat sources (Ivanovic, 2003). Demand for chicken meat increasing day by day resulting increase use of antibiotics, hormone and growth promoter to cope with the increasing demand (Paryad and Mahmoudi, 2008). In TLC analysis the indiscriminate group showed high amoxicillin residual intensity. Chicken liver and kidney contained the highest of proportion of antibiotic residues than the rest of samples. This finding has similarities with the report of Sattar et al. (2014); Sarker et al. (2018); chicken liver contained the highest level of amoxicillin residues than muscles and other viscera. As the liver and kidney is the main metabolic and excretory organs, all drug are metabolized and excreted via liver and kidney chiefly (Sattar et al., 2014). So, even in discriminate groups, the presence of antibiotics residue was found in liver and kidney with high intensity. There are other evidences of similar results where kidney and liver was considered the predilection site of antibiotics residues and analyzed accordingly (Metli et al., 2015). The amoxicillin intensity was lowest in thigh muscle and breast muscle compared to liver and kidney. Relevancy of our result has been found with Al-Mashhadany et al. (2018) with some variations. Data on antibiotic residues in chicken is relatively low in Bangladesh. However, periodic sampling is being carried out in many countries to detect antibiotic residue in the food cycle (Weiss et al., 2007; 
Zhao et al., 2009). Due to the high risk of veterinary drug residues in foods of animal origin, the maximum residues limit (MRL) regulation for use of each pharmacologically active substance has been developed by European Union (EU). The MRL regulation determines the maximum concentrations of residues which are permitted in foods of animal origin and should be followed for public health food safety (Myllyniemi, 2004; Reyes-Herrera et al., 2005). Our study confirms the existing presence of antibiotic residue in our food chain. However, it is necessary to investigate how antibiotic residues enter the human food chain via different ways.

\section{Conclusions}

The deposition and subsequent detection of amoxicillin residue in poultry edible tissue is really a matter of concern. Indiscriminate and irrational use of antibiotics in poultry without following withdrawal period may result in unexpected residues in animal food and could cause serious health hazards to consumers. This research finding is reporting that once antibiotics are administered to animal body, antibiotic residues are present in high or low concentrations in their products. However, it mainly depends on the duration of the administration of antibiotics and maintenance of withdrawal period. After the administration of antibiotic, concentration of their residues gradually reduces mostly after maintenance of withdrawal period secretion of residues is negligible. Hence, the withdrawal time of drugs should be strictly followed. Thus, by observing proper scientific guidelines and precautions we can minimize the harmful effects of antibiotic residues.

\section{Acknowledgements}

We would like express our gratitude and great pleasure to Department of Pharmacology, Bangladesh Agricultural University (BAU) to execute this research work.

\section{Conflict of interest}

None to declare.

\section{References}

Al-Mashhadany DA, A Nahla, AM Zaki and VS Mohammad, 2018. Detection of antibiotic residues among poultry meat in Erbil city and impact of thermal processing on remnants. Res. J. Life Sci. Bioinform. Pharm. Chem. Sci., 3: 237-247.

Alswayeh R, SN Alvi and MM Hammami, 2015. Rapid determination of amoxicillin level in human plasma by high performance liquid chromatography. WJPPS, 4: 1657-1667.

Anadón A, M Martinez-Larrañaga, M Diaz, P Bringas, M Fernandez, M Martinez and M Fernandez-Cruz, 1996. Pharmacokinetics of amoxicillin in broiler chickens. Avian Pathol., 25: 449-458.

Dorrestein G, J Rinzema and M Buitelaar, 1986. Tissue distribution of amoxycillin after oral and intramuscular administration to pigeons (Columba livia). Avian Pathol., 15: 663-676.

Givens D, 2005. The role of animal nutrition in improving the nutritive value of animal-derived foods in relation to chronic disease. Proc. Nutr. Soc., 64: 395-402.

Guetiya Wadoum R, N Zambou, F Anyangwe, J Njimou, M Coman, M Verdenelli and A Cresci, 2016. Abusive use of antibiotics in poultry farming in Cameroon and the public health implications. Br. Poult. Sci., 57: 483493.

Hancu G, B Simon, H Kelemen, A Rusu, E Mircia and A Gyeresi, 2013. Thin layer chromatographic analysis of Beta-lactam antibiotics. Adv. Pharm. Bull, 3: 367-371.

Ivanovic S, 2003. Investigation of the influence of probiotics on the selected indicators of broiler's meat hygiene and quality. PhD Diss. Univ. Belgrade, Serbia, 6: 937-943.

Javadi A, H Mirzaie and S Khatibi, 2011. Effect of roasting, boiling and microwaving cooking methods on enrofloxacin residues in edible tissues of broiler. Afr. J. Pharm. Pharmacol., 5: 214-218.

Khan M, U Sarkar and TK Mandal, 2018. Effect of amoxicillin on haematobiochemical parameters in poultry. Int. J. Livest. Res., 8: 43-51.

Koutoulis K, I Pappas, G Filioussis and L Athanasiou, 2015. Pharmacokinetics and clinical assessment of amoxicillin for the control of necrotic enteritis in broiler-breeders under field conditions. Avian Biol. Res., 8: 89-96.

Metli M, Y Yakar and Y Tekeli, 2015. Determination of antibiotic residues in chicken liver by liquid chromatography-tandem mass spectrometry. Fen Bilimleri Dergisi, 5: 120-131.

Muaz K, M Riaz, S Akhtar, S Park and A Ismail, 2018. Antibiotic residues in chicken meat: Global prevalence, threats, and decontamination strategies: A review. J. Food Prot., 81: 619-627. 
Myllyniemi A-L, 2004. Development of microbiological methods for the detection and identification of antimicrobial residues in meat, 1458: 11-36.

Paryad A and M Mahmoudi, 2008. Effect of different levels of supplemental yeast (Saccharomyces cerevisiae) on performance, blood constituents and carcass characteristics of broiler chicks. Afr. J. Agric. Res., 3: 835842.

Popelka P, J Nagy, R Germuška, S Marcinčák, P Jevinova and A De Rijk, 2005. Comparison of various assays used for detection of beta-lactam antibiotics in poultry meat. Food Addit. Contam., 22: 557-562.

Reyes-Herrera I, MJ Schneider, K Cole, MB Farnell, PJ Blore and DJ Donoghue, 2005. Concentrations of antibiotic residues vary between different edible muscle tissues in poultry. J. Food Prot., 68: 2217-2219.

Sarker YA, MM Hasan, TK Paul, SZ Rashid, MN Alam and MH Sikder, 2018. Screening of antibiotic residues in chicken meat in Bangladesh by thin layer chromatography. Journal of Advanced Veterinary and Animal Research, 5:140-145.

Sattar S, MM Hassan, S Islam, M Alam, MS Al Faruk, S Chowdhury and A Saifuddin, 2014. Antibiotic residues in broiler and layer meat in Chittagong district of Bangladesh. Vet. World, 7: 738-743.

Singh S, S Shukla, N Tandia, N Kumar, and R Paliwal, 2014. Antibiotic residues: a global challenge. Pharma Science Monitor, 5: 184-197.

Tajick MA and B Shohreh, 2006. Detection of antibiotics residue in chicken meat using TLC. Int. J. Poult. Sci., 5: 611-612.

Weiss C, A Conte, C Milandri, G Scortichini, P Semprini, R Usberti and G Migliorati, 2007. Veterinary drugs residue monitoring in Italian poultry: current strategies and possible developments. Food Control, 18: 10681076.

Zhao S, X Li, Y Ra, C Li, H Jiang, J Li and Y Wan, 2009. Developing and optimizing an immunoaffinity cleanup technique for determination of quinolones from chicken muscle. J. Agr. Food Chem., 57: 365-371. 